\title{
Business Impact Analysis Untuk Penanganan Gangguan Bisnis di Lembaga Perbankan
}

\author{
M Hadi Prayitno, Hendarman Lubis \\ Universitas Bhayangkara, Indonesia \\ Email : ${ }^{1}$ hadi.prayitno@dsn.ubharajaya.ac.id
}

\begin{abstract}
Abstrak
Bank merupakan institusi keuangan yang memiliki pengaruh yang sangat besar terhadap sistem perekonomian dalam proses bisnis dan perorangan. Kehidupan kita seakan tidak dapat lepas dari jasa yang ditawarkan perbankan. Memperhatikan hal tersebut membuat regulator harus dapat mengatur kepentingan perbankannya dan juga nasabahnya. Dalam penelitian ini, Lembaga Perbankan telah mengidentifikasi berbagai macam dampak yang dapat mengganggu, dalam proses bisnisnya. Selain itu, telah pula di tentukan jangka waktu toleransi maksimal (MLTD) untuk dilakukan pemulihan bisa terjadi gangguan terhadap bisnis. Dengan adanya Business Impact Analysis, Lembaga Perbankan mengetahui waktu maksimal yang ditoleransi sebelum dipulihkan, dan mengetahui dampak-dampaknya secara financial dan non financial, yang pada akhirnya Lembaga Perbankan dapat mengambil keputusan saat terjadi gangguan bisnis, sehingga memperkecil kerugian yang mungkin ditimbulkan.
\end{abstract}

Kata Kunci: Bank, Business Impact Analysis, Dampak, MLTD

\section{Abstract}

Banks are financial institutions that have a very large influence on the economic system in business processes and individuals. Our lives seem to be inseparable from the services offered by banks. Paying attention to this makes the regulator must be able to regulate its banking interests and customers. In this study, Banking institution has identified various kinds of impacts that can be disruptive, in its business process. In addition, the maximum tolerance period (MLTD) has also been determined for recovery, which can cause disruption to the business. With the Business Impact Analysis, Banking institution knows the maximum time tolerated before being recovered, and knows its financial and non financial impacts, which in the end Banking institution can make decisions when a business has a business interruption, thereby minimizing the losses that might be caused.

Keywords: Banks, Analysis of Business Impacts, Impacts, MLTD

\section{PENDAHULUAN}

Di dalam industry, khususnya dalam perbankan, bencana adalah hal yang tidak diinginkan dan semaksimal mungkin di hindari. Dampak bencana yang terjadi dalam dihindari bila telah teridentifikasi sebelumnya. Maka jika bencana dan atau ganguan itu terjadi maka proses bisnis dapat diselamatkan, khsusnya layanan terhadap stakeholder. Sebelum merancang BIA, perlu untuk mengidentifikasi gangguan-gangguan sejak awal. Gangguan di maksud dapat berasal dari gangguan yang tidak terduga dan atau berasal dari manusia. Identifikasi gangguan tersebut di kumpulkan dan di susun dalam bentuk Business Impact Analysis (BIA).

Tujuan dari BIA adalah mengidentifikasi unit bisnis, operasi bisnis dan proses bisnis yang kritis terhadap kelangsungan perusahaan. BIA mengidentifikasi berapa waktu yang dibutuhkan suatu unit dan proses bisnis kritis untuk kembali beroperasi secara penuh pada situasi bencana (disaster). BIA akan mendefinisikan dampak bisnis dari suatu skenario bencana terhadap kemampuan perusahaan menyediakan produk atau mendukung layanan kritis. BIA juga mengidentifikasikan sumber daya informasi (resources) yang diperlukan agar operasi bisnis dapat terus berjalan pada level survival. Dampak bisnis diidentifikasi berdasarkan skenario terburuk (worst-case scenario) yang mengasumsikan bahwa seluruh infrastruktur fisik yang mendukung setiap unit bisnis telah hancur, begitu juga semua rekam, peralatan, dan lain-lain tidak dapat diakses.

Penelitian ini tidak mengemukakan asumsi pemulihan seperti ketersediaan tenaga berpengalaman untuk pemulihan. Asumsi tersebut merupakan bagian dari Business Continuity Plan (BCP). Isu-isu seperti hal-hal yang perlu diperhatikan untuk pemulihan, ancaman baru, atau tren terbaru pada pemulihan bencana atau kelangsungan bisnis berada di luar lingkup BIA. Keakuratan informasi dan data yang tersedia di laporan ini sangat tergantung dari akurasi dan kelengkapan informasi dan data yang diberikan oleh narasumber.

\section{TEORITIS}

Metode penelitian merupakan prosedur/tahapan dan teknik penelitian. Antara satu penelitian dengan penelitian yang lain, prosedur dan tekniknya akan berbeda. 
mengumpulan data BIA berdasarkan tingkat

gangguan

identifikasi fungsi bisnis, dampak finansial dan non

finansial

Menentukan Maximum Tolerable Period of Disruption

(MTPD) dan Recovery Time Objective (RTO)

Menentukan terget pemulihan

Gambar 1. Metode penelitian

\section{ANALISA DAN PEMBAHASAN}

Agar lebih terarah dalam melakukan Business Impact Analysis (BIA) sebagaimana dalam penelitian ini, proses analisa ini dilakukan berdasarkan metodologi diatas.

(1) Menentukan target dan ruang lingkup

Target dan ruang lingkup dari Business Impact Analysis ini adalah

1. Subsidized mortage

2. Non-Subsidized Mortgage \& Customer Lending

3. Operation \& Business Support
a. Parameter \& Application Administrator
b. Settlement Operation
c. Card \& Financial Reconciliation
d. Channel Operation

4. Digital Channels

5. Service Quality \& Distribution

6. Kantor Cabang

Dari ruang lingkup diatas, secara subyektif yang didapatkan dari

1. Para Kepala Departermen

2. Petugas yang bertanggung jawab terhadap proses bisnisnya

(2) Mengumpulan data BIA

Pada proses ini, berdasarkan pada ruanglingkup diatas, dapat diidentifikasikan tingkat prioritas saat terjadinya gangguan. Tingkat Prioritas tersebut adalah sebagai berikut

1. Sangat Kritikal, hal ini terjadi bila
a. Mengganggu secara sistemik
b. Penurunan kepercayaan stakeholder dan atau public
c. Krusial dan kritis terhadap layanan
d. Tidak memenuhi persyaratan peraturan dan regulator
e. Gangguan bisnis yang besar

2. Dibutuhkan, hal ini terjadi bila

a. Secara tidak langsung mendukung layanan

b. Mematuhi persyaratan peraturan dan regulator

c. Gangguan bisnis yang ditoleransi

3. Tidak Kritikal, hal ini terjadi bila tidak mempengaruhi layanan dan tidak ada keharusan. 
Agar lebih focus terhadap masalah yang dihadapi, maka penelitian ini berfokus kepada gangguan yang memiliki tingkat prioritas yang 'Sangat Kritikal', Seperti tersebut dalam table dibawah ini

Tabel 1. Tingkat Prioritas Gangguan

\begin{tabular}{|c|c|c|}
\hline No & Ruang Lingkup Proses & Sub Proses \\
\hline 1 & $\begin{array}{l}\text { Div Operation \& Business Support, } \\
\text { Bagian Card \& Financial } \\
\text { Reconciliation }\end{array}$ & $\begin{array}{l}\text { 1. Rekonsiliasi sesuai dengan ketentuan Issuer Card principal } \\
\text { dan provider (seperti Link,Bersama, Prima, Alto dan Visa } \\
\text { dll) termasuk transaksi on US. } \\
\text { 2. Rekonsiliasi sesuai dengan ketentuan Acquirer Card } \\
\text { principal dan provider, seperti Link,Bersama, Prima, Alto } \\
\text { dan Visa dll. } \\
\text { 3. Penyelesaian transaksi dan klaim transaksi berbasis kartu, } \\
\text { mesin dan electronic banking. } \\
\text { 4. Membuat Nota Settlement atas transaksi-transaksi yang } \\
\text { Berhasil setelah proses rekonsiliasi }\end{array}$ \\
\hline 2 & $\begin{array}{l}\text { Div Operation \& Business Support, } \\
\text { Bagian Channel Operation }\end{array}$ & $\begin{array}{l}\text { 1. Pengelolaan dan pengawasan infrastruktur E-Banking } \\
\text { ataupun Electronic Delivery Channel. } \\
\text { 2. Memonitor availability dari produk. } \\
\text { 3. Pengembangan fitur dan produk Internet banking, Mobile } \\
\text { banking, ATM, EDC, webbased }\end{array}$ \\
\hline 3 & $\begin{array}{l}\text { Div Operation \& Business Support, } \\
\text { Bagian Parameter \& Application } \\
\text { Administrator }\end{array}$ & $\begin{array}{l}\text { 1. Pengelolaan dan pemeliharaan atau maintenance user ID } \\
\text { Kantor atau Outlet Cabang, Kantor Wilayah dan Kantor } \\
\text { Pusat yang berhubungan dengan aplikasi core banking. } \\
\text { 2. Start Of Day (SOD) \& End Of Day (EOD) atas aplikasi }\end{array}$ \\
\hline 4 & $\begin{array}{l}\text { Div Operation \& Business Support, } \\
\text { Bagian Settlement Operation }\end{array}$ & $\begin{array}{l}\text { 1. Pembayaran untuk penyediaan dana dalam rangka prefund } \\
\text { kliring kredit dan debet. } \\
\text { 2. Settlement atas seluruh transaksi yang berada dalam } \\
\text { wewenang. } \\
\text { 3. Pemeliharaan dan penyediaan dana yang berada di BI, } \\
\text { Bank Kustodian maupun Bank Koresponden. } \\
\text { 4. Pengelolaan transaksi BI-RTGS. } \\
\text { 5. Pengelolaan transaksi Pasar Uang (Money Market) dan } \\
\text { fixed income }\end{array}$ \\
\hline 5 & $\begin{array}{l}\text { Div Non-Subsidized Mortgage \& } \\
\text { Customer Lending }\end{array}$ & $\begin{array}{l}\text { 1. Pembayaran untuk penyediaan dana dalam rangka prefund } \\
\text { kliring kredit dan debet. } \\
\text { 2. Penjualan Produk dan Fitur Non-Subsidized Mortgage, } \\
\text { Equity Loan, dan Consumer Loan. } \\
\text { 3. Pengelolaan surat-surat berharga (Obligasi, Reksa Dana, } \\
\text { NCD dan Surat Berharga BI) transaksi pasar uang }\end{array}$ \\
\hline 6 & Div Service Quality \& Distribution & $\begin{array}{l}\text { 1. Operasional Contact Center. } \\
\text { 2. Pengakurasian data Sistem Layanan Informasi Keuangan } \\
\text { (SLIK) }\end{array}$ \\
\hline 7 & Div Subsidized Mortgage & $\begin{array}{l}\text { 1. Pengembangan dan Penjualan Produk dan Fitur Subsidized } \\
\text { Mortgage }\end{array}$ \\
\hline
\end{tabular}

(3) Identifikasi Dampak

Berdasarkan tingkat Kritikal diatas (Sangat Kritikal), maka dapat diidentifikasikan dampak-dampak yang akan terjadi yang berpengaruh terhadap fungsi finansial dan fungsi non-finansial.

Tabel 2. Identifikasi Dampak

\begin{tabular}{|c|c|c|c|c|}
\hline \multirow{2}{*}{ No } & \multirow{2}{*}{ Proses Kritis } & \multicolumn{3}{|c|}{ Dampak } \\
\hline & & Finansial & & Non-Finansial \\
\hline 1 & $\begin{array}{l}\text { Operasional Contact Center (Div Service } \\
\text { Quality \& Distribution) }\end{array}$ & Kompensasi Pembayaran & & Reputasi \\
\hline 2 & $\begin{array}{l}\text { 1. Pembayaran untuk penyediaan dana } \\
\text { dalam rangka prefund kliring kredit } \\
\text { dan debet. (Div Settlement Operation) } \\
\text { 2. Start Of Day (SOD) \& End Of Day } \\
\text { (EOD) atas aplikasi (Parameter \& } \\
\text { Application Administrator). }\end{array}$ & $\begin{array}{l}\text { 1. Kompensansi Bunga } \\
\text { 2. Tambahan Biaya } \\
\text { Biasa }\end{array}$ & Luar & $\begin{array}{l}\text { 1. Kegagalan Kliring } \\
\text { 2. Reputasi } \\
\text { 3. SLA tidak tercapai } \\
\text { 4. Teguran Dari Regulator }\end{array}$ \\
\hline
\end{tabular}




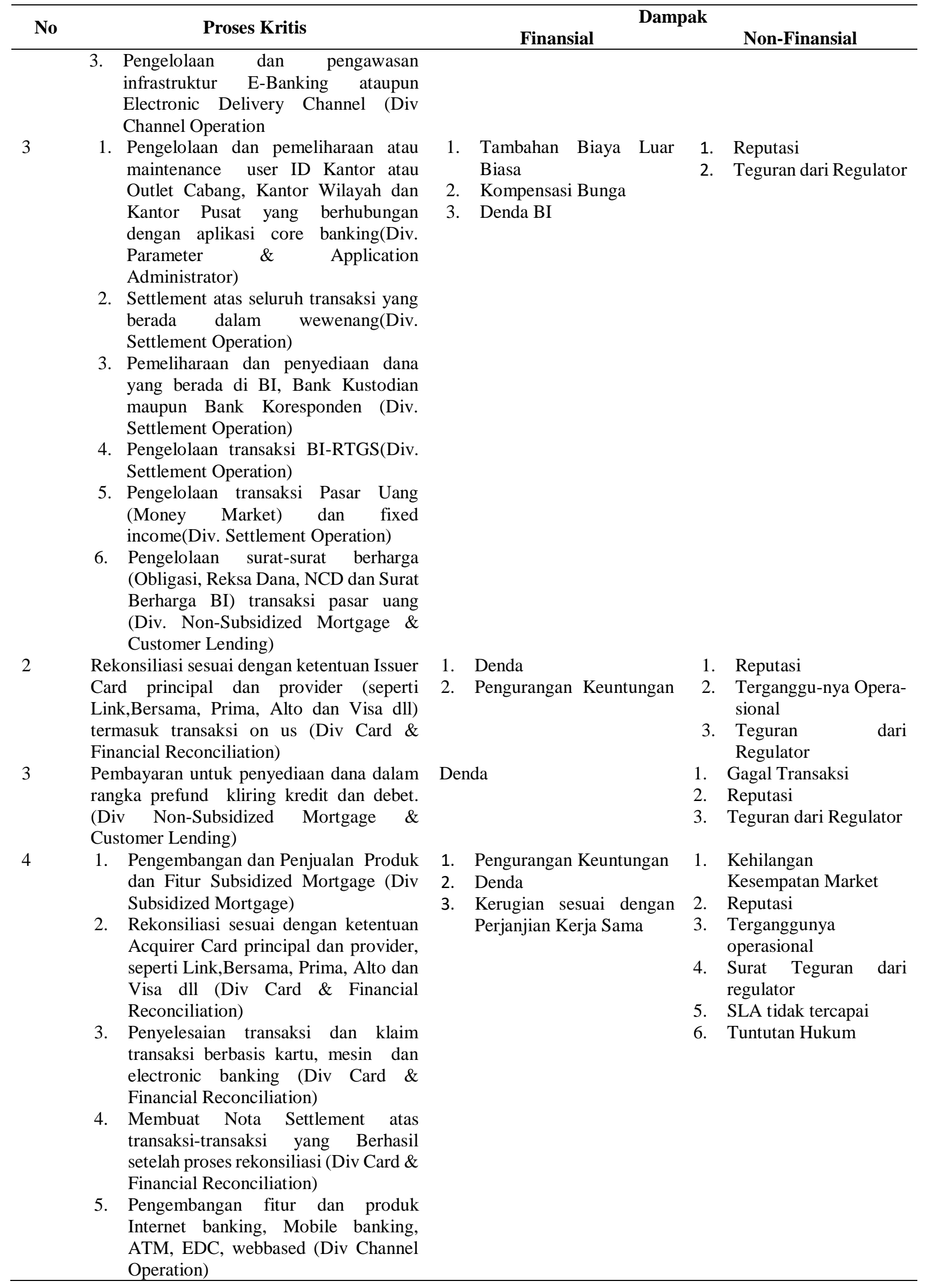




\begin{tabular}{|c|c|c|c|c|}
\hline \multirow{2}{*}{ No } & \multirow{2}{*}{ Proses Kritis } & \multicolumn{3}{|c|}{ Dampak } \\
\hline & & Finansial & & Non-Finansial \\
\hline & $\begin{array}{l}\text { 6. Penjualan Produk dan Fitur Non- } \\
\text { Subsidized Mortgage, Equity Loan, } \\
\text { dan Consumer Loan (Div Non- } \\
\text { Subsidized Mortgage \& Customer } \\
\text { Lending) }\end{array}$ & & & \\
\hline & $\begin{array}{l}\text { 7. Pengakurasian data Sistem Layanan } \\
\text { Informasi Keuangan (SLIK) (Div } \\
\text { Service Quality \& Distribution) }\end{array}$ & & & \\
\hline 5 & $\begin{array}{l}\text { Memonitor availability dari produk (Div } \\
\text { Channel Operation) }\end{array}$ & $\begin{array}{l}\text { Kerugian berasal } \\
\text { kegagalan produk }\end{array}$ & dari & Reputasi \\
\hline
\end{tabular}

(4) Menentukan Maximum Tolerable Period of Disruption (MTPD) dan Recovery Time Objective (RTO) Dengan memperhatikan dampak yang akan terjadi diatas, maka dapat ditentukan Maximum Tolerable Period of Disruption (MTPD) - lamanya waktu yang bisa ditoleransi apabila Lembaga Perbankan kehilangan kemampuan untuk melakukan proses bisnis tersebut (semua sumber daya hilang - orang, data, sistem informasi, dan lain-lain) dan Recovery Time Objective (RTO) - waktu yang dibutuhkan untuk memulihkan untuk kembali ke kondisi semula. MTPD dan RTO ini didapat berdasarkan prioritas beban dalam aktivitas bisnis yang diuangkap oleh para petugas lembaga keuangan dimaksud

Tabel 3. Nilai MTPD dan RTO

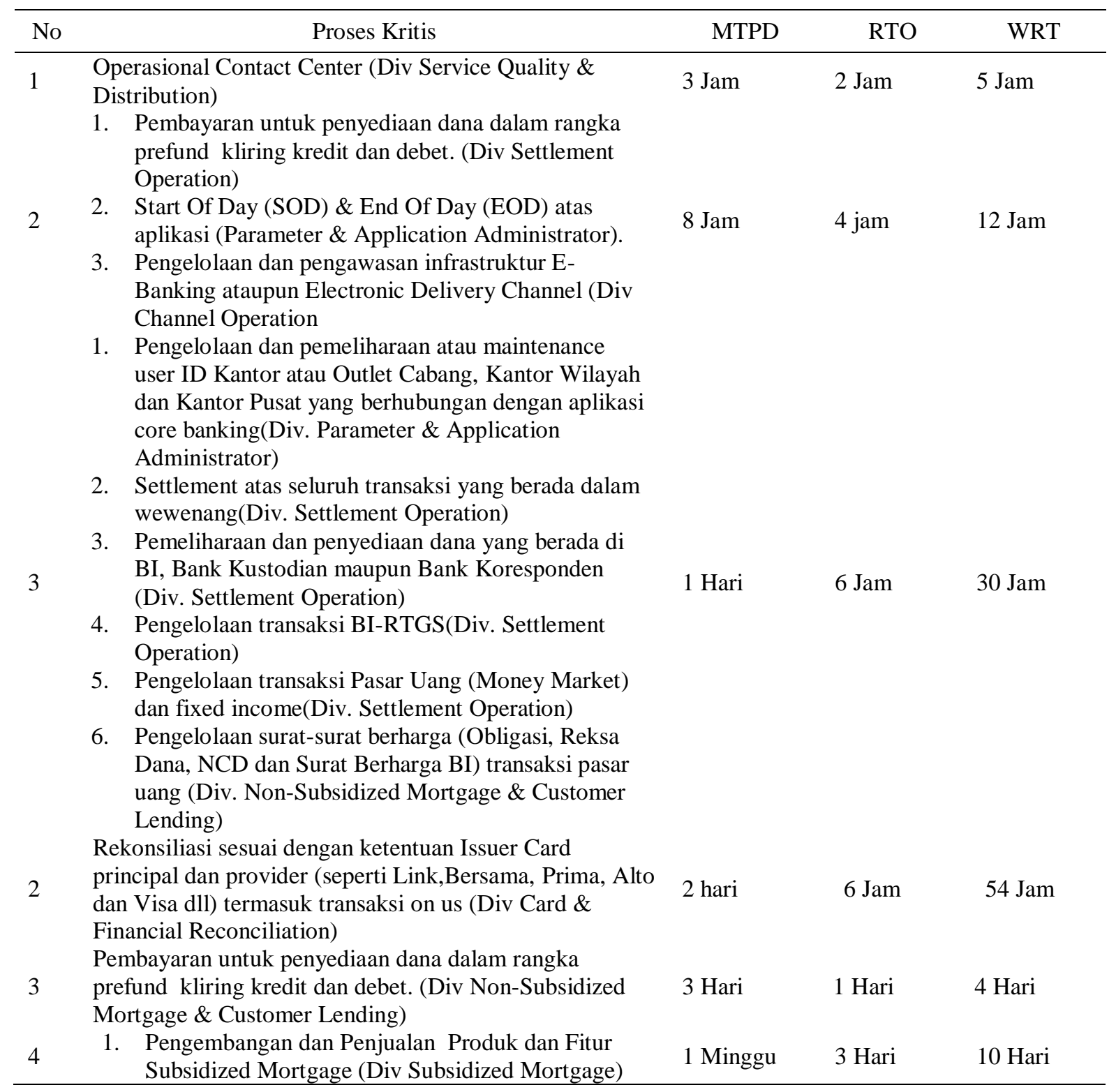




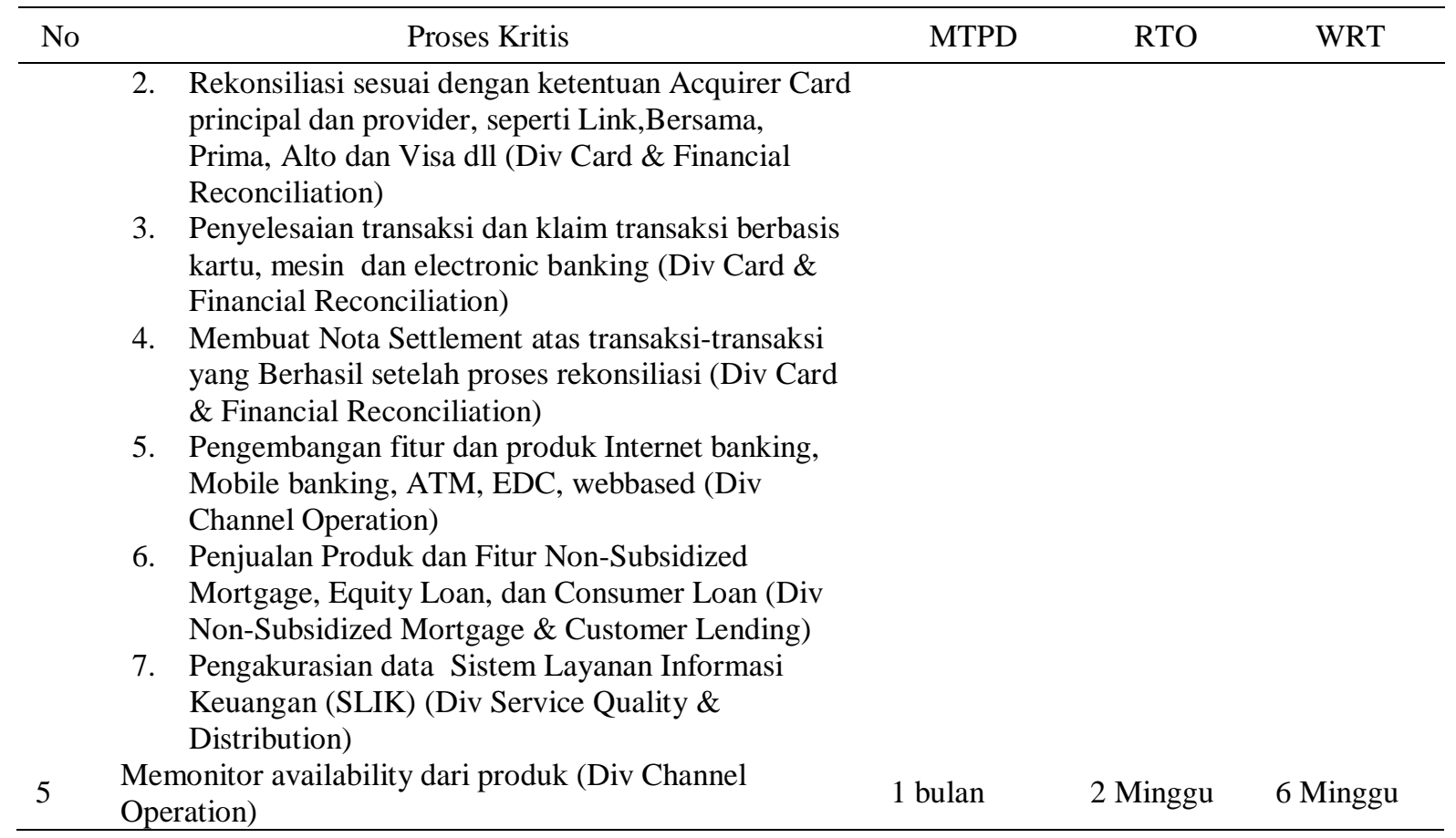

(5) Menentukan terget pemulihan

Setelah mengetahui MTPD dan RTO pada setiap identifikasi gangguan yang bersifat 'Sangat Kritis' diatas, maka perlu membatasi proses-proses yang seharusnya dipulihkan terlebih dahulu dengan memperhatikan keterbatasan waktu pelaporan, khususnya pelaporan terhadap Bank Indonesia, Proses yang harus dipulihkan saat dimulainya terjadi gangguan adalah

Tabel 4. Target Pemulihan

\begin{tabular}{|c|c|c|c|}
\hline \multirow{2}{*}{ No } & \multirow{2}{*}{$\begin{array}{l}\text { Batas Hari } \\
\text { Pemulihan }\end{array}$} & \multicolumn{2}{|c|}{ Yang harus dipulihkan } \\
\hline & & Divisi & Proses \\
\hline 1 & 1 hari & $\begin{array}{l}\text { Div Channel Operation } \\
\text { Div Service Quality \& Distribution } \\
\text { Div Settlement Operation }\end{array}$ & $\begin{array}{l}\text { Pengelolaan dan pengawasan infrastruktur E- } \\
\text { Banking ataupun Electronic Delivery Channel } \\
\text { Operasional Contact Center } \\
\text { Pembayaran untuk penyediaan dana dalam } \\
\text { rangka prefund kliring kredit dan debet. } \\
\text { Settlement atas seluruh transaksi yang berada } \\
\text { dalam wewenang } \\
\text { Pemeliharaan dan penyediaan dana yang } \\
\text { berada di BI, Bank Kustodian maupun Bank } \\
\text { Koresponden } \\
\text { Pengelolaan transaksi BI-RTGS } \\
\text { Pengelolaan transaksi Pasar Uang (Money } \\
\text { Market) dan fixed income }\end{array}$ \\
\hline & & $\begin{array}{l}\text { Div. Non-Subsidized Mortgage \& } \\
\text { Customer Lending }\end{array}$ & $\begin{array}{l}\text { Pengelolaan surat-surat berharga (Obligasi, } \\
\text { Reksa Dana, NCD dan Surat Berharga BI) } \\
\text { transaksi pasar uang }\end{array}$ \\
\hline & & $\begin{array}{l}\text { Div. Parameter \& Application } \\
\text { Administrator }\end{array}$ & $\begin{array}{l}\text { Start Of Day (SOD) \& End Of Day (EOD) atas } \\
\text { aplikasi }\end{array}$ \\
\hline & & & $\begin{array}{l}\text { Pengelolaan dan pemeliharaan atau } \\
\text { maintenance user ID Kantor atau Outlet } \\
\text { Cabang, Kantor Wilayah dan Kantor Pusat yang } \\
\text { berhubungan dengan aplikasi core banking }\end{array}$ \\
\hline 2 & 2 hari & Div Card \& Financial Reconciliation & $\begin{array}{l}\text { Rekonsiliasi sesuai dengan ketentuan Issuer } \\
\text { Card principal dan provider (seperti } \\
\text { Link,Bersama, Prima, Alto dan Visa dll) } \\
\text { termasuk transaksi on us }\end{array}$ \\
\hline
\end{tabular}




\begin{tabular}{llll}
\hline No & $\begin{array}{c}\text { Batas Hari } \\
\text { Pemulihan }\end{array}$ & \multicolumn{1}{c}{ Divisi } & \multicolumn{2}{c}{ Yang harus dipulihkan } \\
\hline 3 & 3 hari & $\begin{array}{l}\text { Div Non-Subsidized } \\
\text { Customer Lending }\end{array}$ & Mortgage \& \\
4 & 1 minggu & $\begin{array}{l}\text { Pembayaran untuk penyediaan dana dalam } \\
\text { rangka prefund kliring kredit dan debet. }\end{array}$ \\
\hline
\end{tabular}

\section{KESIMPULAN}

Business Impact Analysis ada sebuah proses yang ditujukan untuk memberi acuan kepada pengusaha (khususnya dalam penelitian ini adalah Lembaga Perbankan). Berdasarkan ruang lingkup, telah dilakukan identifikasi waktu yang ditoleransi saat Lembaga Perbankan kehilangan kemampuannya untuk menjalankan proses bisnisnya (MTPD). Ketidak mampuan tersebut akan menimbulkan dampak finansial dan dampak non finansial. Agar risiko dampak dimaksud dapat dihindari, maka perlu memperhatikan tingkat kritikal, sehingga dapat segera diambil langkah untuk dilakukan pemulihan, yang akhirnya bisnis dapat berjalan normal kembali.

Agar hasil dari Business Impact Analysis ini dapat memberikan masukkan, khususnya bagi Lembaga Perbankan, maka perlu dilakukan dan atau dibentuk tim untuk menangani Business Continuity Strategy, dan perlu pula dikembangkan strategi penyimpanan data dan atau backup agar memperkecil kemungkinan terhentinya proses bisnis dan kehilangan data.

\section{REFERENCES}

[1] Badan Sertifikasi Manajemen Risiko, (2007), Indonesia Certificate in Banking Risk an Reguklation, Badan Sertifikasi Manejmen Risiko

[2] Irham fahmi (2010), Manajemen Risiko, Teori, Kasus dan Solusi, Alfabeta

[3] ISO 22313, (2012), Draft International Standart ISO 22313

[4] Depertemen Keuangan RI, Surat Edaran Otoritas Jasa Keuangan No 34/SEOJK.03/2016, Penerapan manajemen Risiko Bagi Bank Umum, Indonesia

[5] Jurnal Fitria Chandrawaty (2014), "Perancangan Business Continuity Analysis Pada Divisi IT PT X Untuk Menentukan Business Continuity Strategy", Jurnal, E-Journal Graduate Unpar, Part A :Economic, Volume 1 No 2 (2014), ISSN : $2355-4304$.

[6] Rubil(2012), "Business Impact Analysis Terkait Penangan dan Pemulihan Terhadap Bencana di PT Bank XYZ", ComTech Vol.3 No. 2 Desember 2012, ISSN 2087-1224.

[7] Keefe Darius Chandra (2017),'Penerapan business Continuity Pada Bank Central Asia”, Bina Ekonomi, Jurnal Ilmiah Fakultas Ekonomi Universitas Kristen Parahiyangan, Volume 21 Nomor 1, 2017, ISSN 0853-0610, E-ISSN 2442-675X. 